\title{
XXXII. The ionization ranges of the $\alpha$ rays of actinium
}

\section{O. Hahn Ph.D.}

To cite this article: O. Hahn Ph.D. (1906) XXXII. The ionization ranges of the $\alpha$ rays of actinium, Philosophical Magazine Series 6, 12:69, 244-254, DOI: 10.1080/14786440609463539

To link to this article: http://dx.doi.org/10.1080/14786440609463539

$$
\text { 曲 Published online: } 16 \text { Apr } 2009 .
$$

Submit your article to this journal

\section{山 Article views: 3}

Q View related articles $\square$ 


\section{[ 244$]$}

XXXII. The 7onization Ranges of the a Rarys of Actinium. By O. HaHN, Ph.D.*

TN previous papers $+\mathrm{I}$ gave an account of the methods employed to determine the ranges in air of the ionization due to the varions $x$ ray products of thorium. This paper contains a similar investigation for the ranges of the $\alpha$ rays emitted by the products of actinium. Apart from the physical importance of accurately determining the range in air of the a rays from each of the products, I have found these investigations of great value in throwing light on the successive changes which occur in the new product radioactininm $\ddagger$.

In this paper, therefore, an account will be given of the determination of the ranges in air of the a particles from the following products :--

(1) Active Deposit of Actinium.

(2) Actinium $X$.

(3) Radioactinum.

(4) Actinium emanation.

The preparations used for the experiments were :-

(1) Actinimo (Emanium), activity about 300, prepared by Giesel, provided by Rutherford.

(2) Actinium, activity about 700, prepared by Debierne, kindly lent to me by Sir William Ramsay.

The apparatus employed was the same as previously used for thorium, and similar to that employed by Bragg and Kleeman in their investigations of the ranges of the $a$ rays from the radium products. It is, therefore, not necessary to give again the details of its construction and the method of use.

As I pointed out in my last paper, the chief difficulty in the investigations on thorium arose from the strong emanating power of all the preparations containing thorium $\mathrm{X}$. In order to avoid, as far as possible, the disturbances due to the emanation, the active preparation was placed inside a funnel, and a constant air-current passed through this funnel in order to carry away the emanation. This arrangement had worked satisfactorily at some distance of the active preparation from the ionization-chamber, but for small distances disturbances were not to be avoided. In some cases, a thin mica screen completely enclosed the radioactive preparation in order to prevent the escape of the emanation.

* Conmunicated by Prof. E. Rutherford, F.R.S.

† Phil. Mag. June \& July 1906.

† O. Hahn,' Nature,' April 1906. 
In the case of actinium, the disturbances due to its emanatiou were even greater than in the case of thorium, since the decay period of actinium emanation (half value in $3 \cdot 7$ seconds) is so rapid that by far the greater part of it is transformed before it can be removed even by a very strong air-current. Consequently, disturbances due to the emanation were always encountered, and the only way of avoiding this difficulty completely was to cover the emanating preparation by a mica screen and to determine the "stopping power" of the covering screen by a special experiment.

\section{Ionization Curve of the Active Deposit of Actinium.}

It was of special interest to determine the ionizationdistance curve of the active deposit of actinium, as previous experiments with the active deposit of thorium had conclusively shown that the latter consisted of two well-marked a ray products instead of one as formerly supposed.

The investigation of the active deposit of actinium does not present any of the above-mentioned difficulties, as it can easily be obtained in a pure state in the form of an extremely thin film.

The active deposit was obtained on a thin copper wire, about $1 \mathrm{~cm}$. long, by making it the only negatively-charged body exposed to the emanation of a fairly large amount of actinium. The measurements of the ionization curve were begun about 10 or 15 minutes after removal from the emanation. After that interval, the activity of the active deposit decays nearly according to an exponential law with the period of 36 minutes. The values of the current obtained at different times had, consequently, to be corrected for their decay of activity, and this was easily done by extrapolation from the known decay curve.

Since the activity of the wire was initially not very great and decayed rapidly during the experiment, only about onehalf of the ionization curve could be accurately obtained with one active wire before the activity became very small. The curve was, consequently, completed by using another active wire. In this way the ionization curve could be obtained with accuracy.

Fig. 1 shows the curve obtained for the active deposit of actinium.

From the shape of the curve it is obvious that the active deposit of actinium contains only one a ray product. The ionization of the a rays begins at a distance of $5.50 \mathrm{cms}$., increases very rapidly, reaches a maximum at about $3 \cdot 6$ criss., and decreases slowly with the distance from the source. The 
ionization was measured within $1.0 \mathrm{~cm}$. from the active wire ; and as it is very unlikely that a new set of $\alpha$ particles should enter the ionization-chamber beiow $1.0 \mathrm{~cm}$., we have to conchude that the active deposit of actinium emits one set of

Fig. 1.

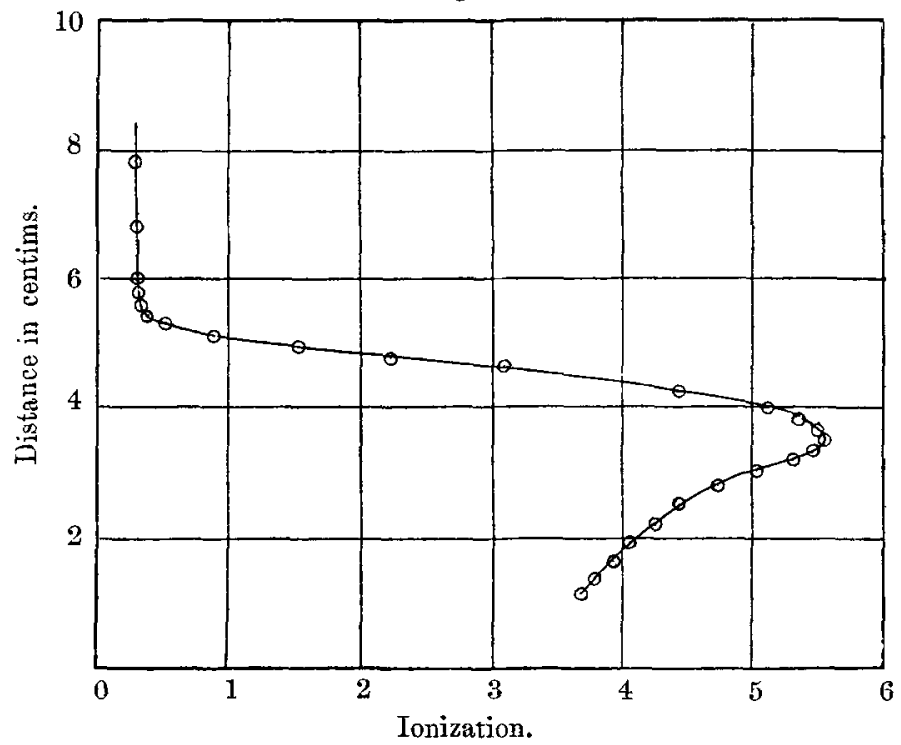

a particles which are able to traverse a distance of $5.50 \mathrm{cms}$. of air. Since the active deposit of thorium emits two different kinds of a rays, we see here one interesting point of distinction in the disintegration series of thorium and actinium.

\section{Ionization Curve of Actinium X.}

The determination of the exact range of the a particles emitted from actinium $\mathrm{X}$ presents very great difficulties on account of the continuous production of emanation from it. The actinium $\mathrm{X}$ was prepared by the well-known method used for the separation of thorium $\bar{X}$ as described in the previous communication. When precipitating the actinium solution with ammonia, the precipitate as a whole does not come down at once. If one filters therefore too early, the filtrate, at first quite clear, soon becomes cloudy, and another small precipitate can be obtained. For the purpose of the experiment a very thin film of actinium $\mathrm{X}$ is required, and for this purpose a 
clear filtrate must be used. Great care has to be taken to use pure chemicals, and it is always advisable to use as little liguid and reagents as possible.

The actinium $\mathrm{X}$ is evaporated on a flat platinum cover and heated to drive off any remaining ammonia salts. As the active deposit is regenerated very quickly, it is difficult to obtain an ionization curve of actinium $X$ alone, for there is always some actinium $B$ present. Since, as we shall see later, the range of the $\alpha$ particles of actinium $\mathrm{X}$ is higher than the range of those of actinium $B$ and of the emanation, the presence of the latter products does not interfere with the accurate determination of the maximum range of actinium $\mathrm{X}$.

In the earlier experiments, great difficulties were encountered in determining the real range of the $\alpha$ particles of actinium $\mathrm{X}$, on account of disturbances due to the emanation even when a strong air-current was used. A small ionization was observed even to a distance of more than $8 \mathrm{cms}$. ; and, in consequence, it was at first thought that traces of thorium $\mathrm{X}$ and, therefore, thorium $\mathrm{C}$ were present. Finally, however, these effects were found to be due only to the presence of the emanation.

In order to obtain accurate results, it was found necessary to cover the actinium $\mathrm{X}$ hermetically with a thin layer of mica. The mica plate was waxed down close to the bottom of the dish, and the small amount of the active matter on the sides of the dish was covered with tinfoil to absorb the a rays, but even in that case a small amount of emanation coming from the walls escaped into the gas.

A separate experiment showed that the mica screen was equivalent in stopping power to $1.20 \mathrm{~cm}$. of air, and in the curves given in fig. 2 the distance is corrected for this absorption of the screen.

Fig. 2 (p. 248) shows the curves obtained for actinium X.

Curve $a$ represents the ionization curve of the freshly prepared product.

Curve $b$ represents the ionization curve 15 days later.

Curve $c$ represents the ionization curve 42 days old.

In the figure, the ionization due to the $\alpha$ rays begins at about $6.55 \mathrm{cms}$. This number gives the average of several experiments, and is probably correct within $1 \mathrm{~mm}$. The ionization curves, after different intervals, are given to show that the curves obtained are really dne to actinium $\mathrm{X}$, which Godlewski has shown decays to half value in 10 days.

In consequence of the use of the mica screen, it is not possible to obtain the shape of the ionization curve closer to 
the source than is shown in fig. 2. Although the rays of the emanation and actinium $B$ are present, they do not interfere with the determination of the maximum range of actinium $X$. The absence of any well-marked breaks in the

Fig. 2.

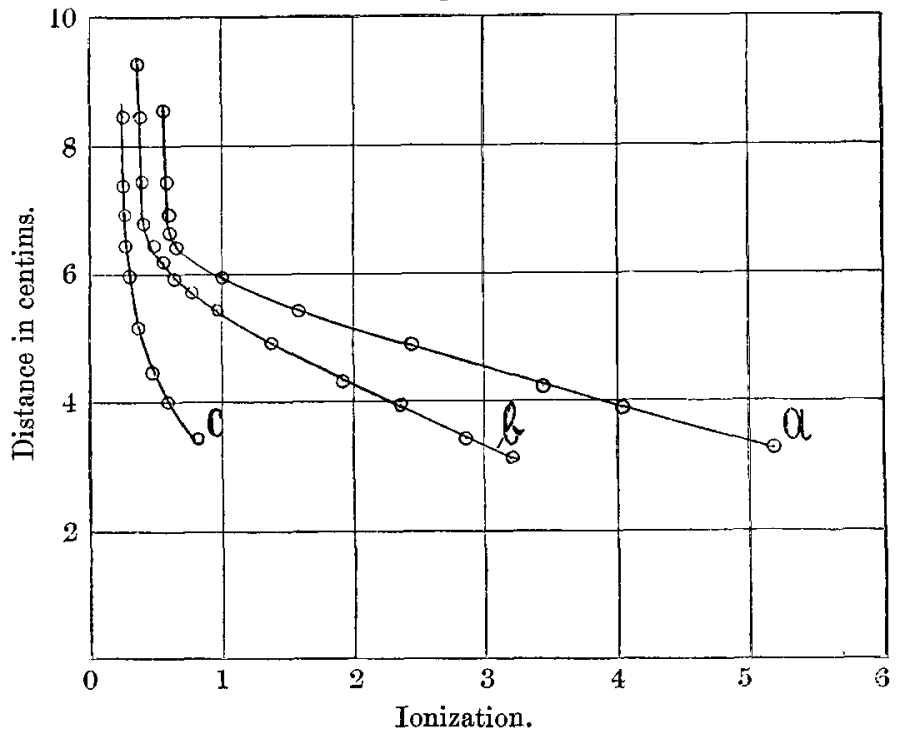

curves is to be expected since the emanation and actinium $B$ have about the same range in air, and the cone of rays was not very narrow.

The result thus shows that the $\alpha$ particles of actinium $\mathbf{X}$ have an ionization range in air of about $6.55 \mathrm{cms}$.

\section{lonization Range of the a Particles of Radioactinium.}

This product in the series of changes is intermediate between actinium and actinium $X$. It is transformed into actinium $X$ and its successive products. Radioactinium emits only $\alpha$ rays, and is half transformed in about 20 days*. A full account of its properties is reserved for a later paper, but it is of interest to show how the determination of the ionization curves of this product at different times throws light on its position among the transformation products of actinium.

The radioactinium used in this investigation was separated by soveral distinct methods, but the simplest form of separa-

* The period of 20 days, as given above, is only approximate and probably slightly too high. 
tion was similar to that employed for the separation of radiothorium from its products. The actinium solution was precipitated successively five times with ammonia in order to completely remove the actinium $\mathrm{X}$. As in the case of radiothorium, the later precipitations are not complete, that is, ammonia is not added to a sufficient extent to carry down the actinium itself. By this procedure, the radioactinium is concentrated in the first precipitate, while the actinium remains for the most part in the solution. It is not difficult to obtain a layer thin enough for the determination of the ionization curve.

Fig. 3.

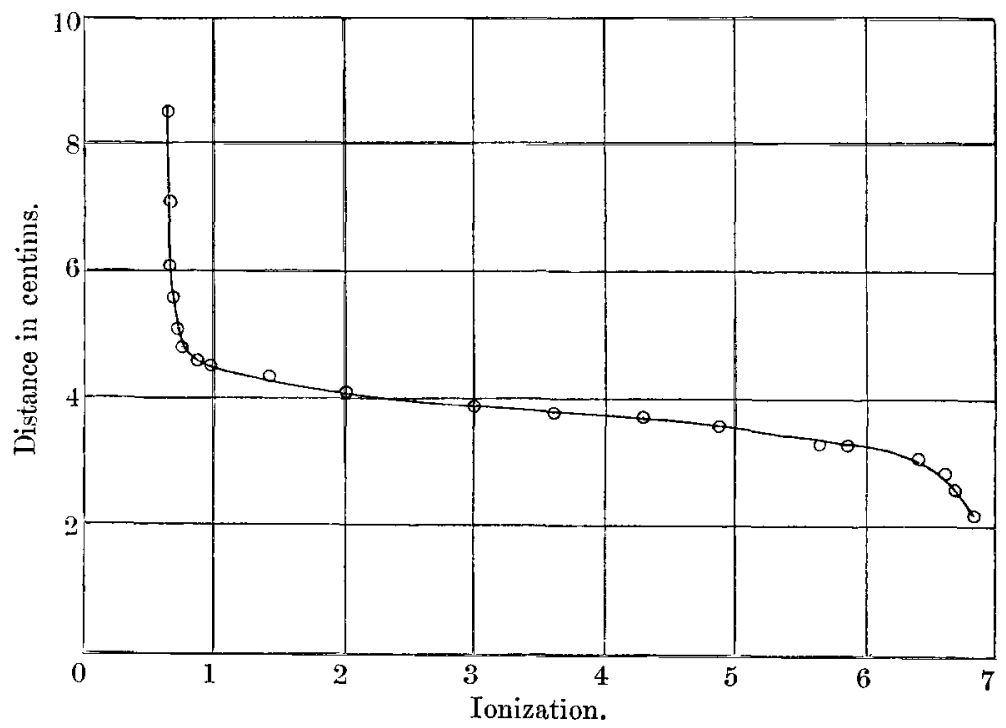

Fig. 3 shows the curve for radioactinium when completely freed from actinium $X$ and also the active deposit. As the activity of the specimen was not very strong, the scale of abscissæ is increased in the ratio 2.5 of that employed in the other figures.

It is seen that the curve of radioactinium has the characteristic shape for a thin film of a single $\alpha$ ray product. The maximum range of the $\alpha$ rays is $4.8 \mathrm{cms}$., and this value is probably correct within half a millimetre. Since radioactinium at first increases in activity due to the production of actinium $X$ and its successive products, we should expect to obtain evidence from the ionization curve of the presence of these products. This is seen to be the case. 
The curves $b$ and $c$, fig. 4 , show the curves obtained 4 and 21 days respectively after preparation. The curve $a$ represents the normal curve of radioactinium itself immediately after

Fig. 4.

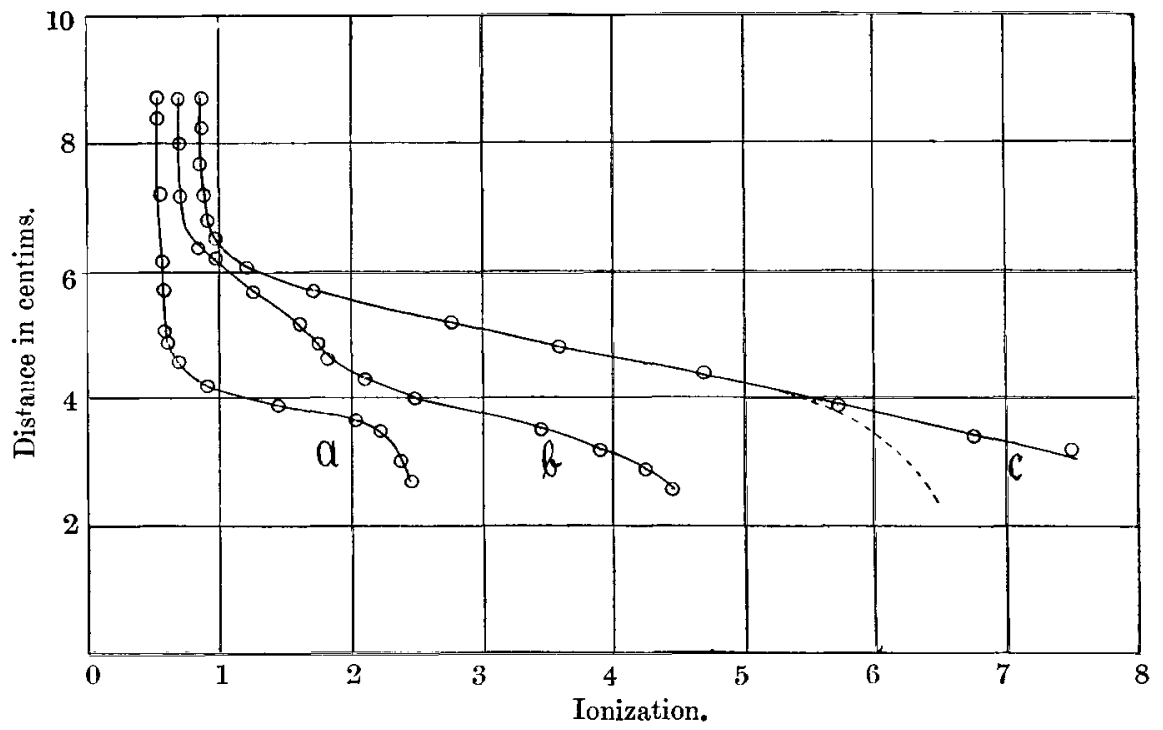

separation on the same scale. It is seen from curves $b$ and $c$ that the ionization commences to increase at a distance of about $6.6 \mathrm{cms}$. This is due to the $\alpha$ rays from actinium $\mathrm{X}$, which we have seen have a range of $6.55 \mathrm{cms}$.

The activity of a preparation of radioactinium reaches a maximum about 20 days after preparation. The curre $c$, obtained about that time, is more regular than $b$, and no sudden changes of slope of the curve can be noticed.

The marked disturbance produced by the emanation was clearly shown by variation of the experimental conditions. The set of brass tubes $1 \cdot 1 \mathrm{~cm}$. high was removed and a similar set of tubes $0.4 \mathrm{~cm}$. high substituted. In this case, the air-current removes a greater portion of the emanation. The lower part of the curve obtained in this way showed a distinct bend downwards. In another experiment the air-current was interrupted. The emanation consequently diffused upwards, and the curve obtained near the source bent upwards instead of downwards. Possibly better results would have been obtained if holes had been bored through the active porcelain crucible in order to allow a more direct action of the air-current. 


$$
\text { of the a Rays of Artinium. }
$$

The curves in fig. 4 do not of themselves show whether the radioactinium preparation was initially freed from actinium, for the latter does not emit any rays. The activity of radioactinium and its products after reaching a maximum in about 20 days commences to decay and ultimately, according to an exponential law, with a period of about 20 days. If actinium were present the activity of the preparation would not decay to zero, but would finally reach a constant value depending on the amount of actinium present. This is obviously the case, since actinium gives rise to radioactinium and its successive products.

Fig. 5.

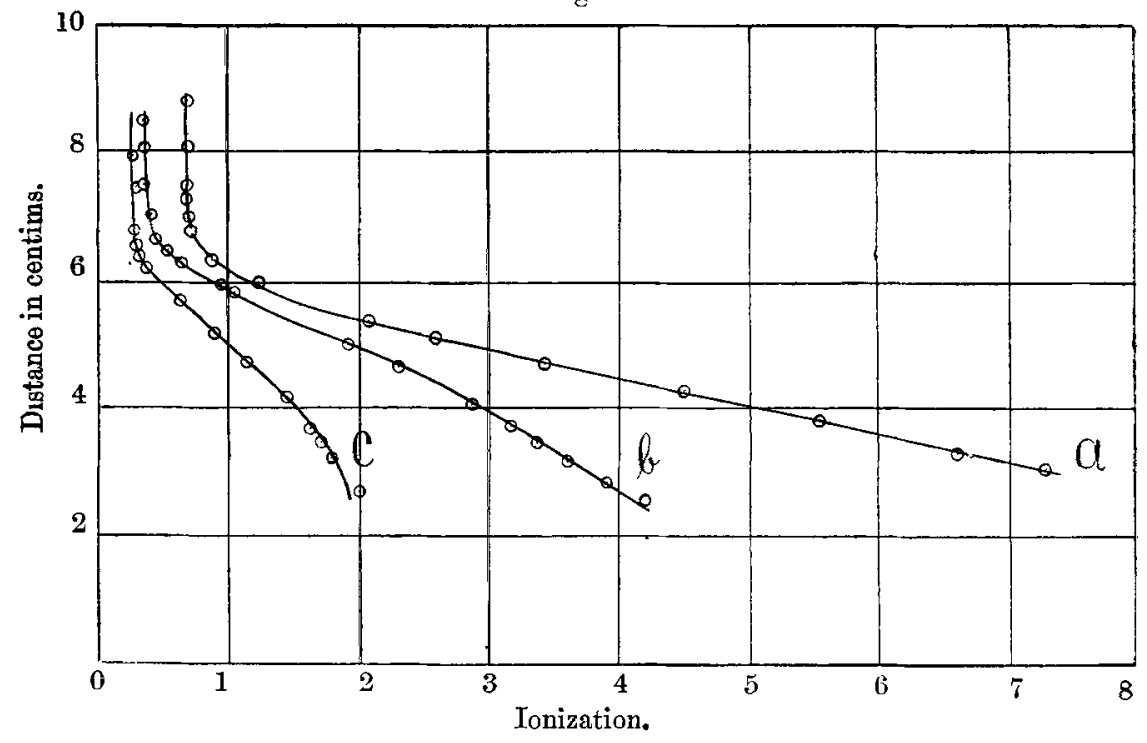

We see, however, from the curve shown in fig. 5 that no sensible amount of actinium could have been present. Curve $a$ is the same as curve $c$ in fig. 4 , and is due to radioactinium at its maximum activity when in equilibrium with its successive products. The curves $b$ and $c$ were obtained 39 and 71 days respectively after a maximum had been reached. It is seen that the curves are all similar, showing that the activity due to each product decays at the same rate. The initial activities, due to the $\beta$ rays and the natural leak of the vessel, are partly increased (curve $a$ ), partly decreased (curve $c$ ), in order to show distinctly the initial portions of the three curves separated from one another. The ionization (curve $c$ ) begins very nearly at the correct maximum range 
of the a particles of actinium X, viz. $6 \cdot 6 \mathrm{cms}$., but the ionization due to the $\alpha$ rays, shown in the curves $a$ and $b$, begins somewhat higher than this-a difference due to the presence of the emanation for the reasons discussed above.

The three curves are very similar to the curves obtained for actinium $X$, shown in fig. 2, the only difference being that the rays of radioactinium begin to add their effect at a distance of $4.8 \mathrm{cms}$. This, however, is not easy to observe in the figure.

A striking difference is shown, however, in the rates at which the ionization falls off with time. The ionization of actinium $\mathrm{X}$ decreases exponentially with a period of ten days, and is hardly distinguishable after about 50 days. The ionization of radioactinium, however, decreases at a much slower rate, and the ionization after two months' interval is still very marked.

The decay of the radioactinium preparation could, of course, have been measured in an ordinary electroscope, but this of itself would not have shown whether actinium $\mathrm{X}$ and its products were present when the activity had reached a small value. In fact, the ionization curves serve as a means of radioactivity analysis to show what a ray products are present.

\section{The Range of the a Particles of the Actinium Emanation.}

The method used for determining the range of the $\alpha$ particles of the actinium emanation was exactly the same as that used by the writer for the thorium emanation, which was described in the previous paper*. The emanation was passed with a slow air-current through a flat vessel, the top of which consisted of a thin mica plate, the stopping power of which had been determined by a special experiment. A small sensitive zinc-sulphide screen was placed vertically above the mica and could be brought to any desired distance. The point, where scintillations just began to be visible, was taken as the maximum range of the a particles when using the scintillation method.

I previously pointed out that the ranges of a particles determined by the electrical method seemed to be nearly $3 \mathrm{mms}$. greater than those determined by the scintillation method as above described. This difference may, possibly, vary somewhat with different observers.

Taling the mean of several measurements, which were in

$$
\text { * Loter at. }
$$


good agreement with one another, the range at which the a particles of the actinium emanation cease to ionize the air (including the correction of $0.3 \mathrm{~cm}$. for the electrical method and $1.2 \mathrm{~cm}$. for stopping power of the mica screen) was found to be about $5.8 \mathrm{cms}$.

The ranges of the $\alpha$ ray products of actinium are shown in the following table. For completeness the ranges of the products of thorium, determined by the writer, and of radium, determined by Bragg and Ǩleeman, are added for comparison.

With the exception of the $\alpha$ rays from uranium, the ranges in air of the $\alpha$ particles expelled from all the products of the radioelements have now been determined accurately.

TAble I.

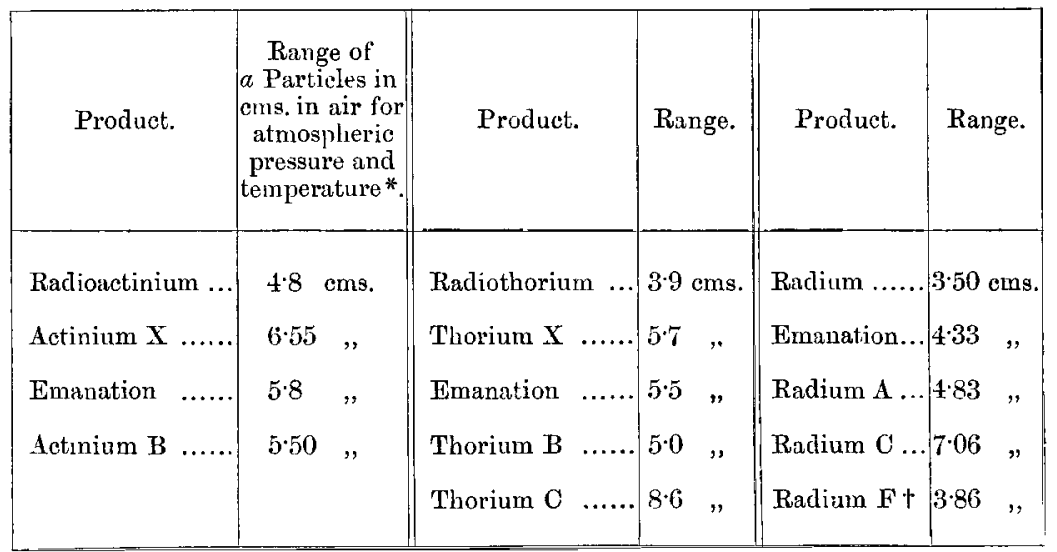

* The pressure during the period of this investigation did not vary to suck an extent as to produce marked differences in the ranges.

+ Determined by M. Levin, Americ. Journ. Science, July 1906.

It is seen that the ranges of the $\alpha$ particles from thorium differ among each other to a greater extent than those of radium, and the latter to a greater extent than those of actinium. For example, the extreme difference in the ranges for the thorium products is $4 \cdot 7$ cms., for radium products $3.56 \mathrm{cms}$, while for actinium it is only $1.75 \mathrm{~cm}$.

A comparison of the ranges of the $\alpha$ particles from thorium and actinium shows a very interesting relationship. In the table below the products are arranged in the order of magnitude of the ranges of their $\alpha$ particles. 
TABLE II.

\begin{tabular}{|c|c|c|c|}
\hline $\begin{array}{l}\text { Range of } \\
a \text { Particles. }\end{array}$ & Product. & $\begin{array}{l}\text { Range of } \\
a \text { Particles. }\end{array}$ & Product. \\
\hline $4.8 \mathrm{cms} . . . .$. & Radioactinium. & $3.9 \mathrm{cms} . . . . .$. & Radiothorium. \\
\hline $550 \quad, \ldots \ldots$ & Actinium B. & $5 \cdot 0 \quad$, & Thoriuin B. \\
\hline $5 \cdot 8 \quad, \quad \ldots \ldots$ & Emanation. & $5.5 \quad \ldots$. & Emanation. \\
\hline \multirow[t]{2}{*}{$6: 55, \quad, \ldots \ldots$} & Actinium $\mathbf{X}$. & $5 \cdot 7, \ldots \ldots$ & Thorium $\mathbf{X}$. \\
\hline & & $8 \cdot 6, \ldots \ldots$ & Thorium $\mathrm{C}$. \\
\hline
\end{tabular}

It is seen that each of the products of thorium and actinium occupies a corresponding place in the table, the only difference being that there is no product in actinium corresponding to thorium $\mathrm{C}$ in thorium.

The similarity in the number and nature of the products of these two elements bas often been pointed out, and the relationship described above is probably more than a coincidence, and indicates that there is a close connexion in the mode of transformation of the atoms of thorium and actinium.

In conclusion I again wish to express my best thanks to Professor Rutherford for his usual interest he took in this work, and for the kind advice I received from him.

The Macdonald Physics Building,

Montreal, June 10th, 1906.

XXXIII. The Molecular Structure of Metals. By J. A. EwIng, LL.D., F.R.S., M.Inst.C.E.*

INTEND to devote this Address to considering in certain aspects the inner structure of metals and the manner in which they yield under strain. It will not be disputed thas this is a primary concern of the engineer, who in all his problems of design is confronted by the limitations imposed on him by the strength and elasticity of the materials he employs. It is a leading aim with him to secure lightness and cheapness by giving to the parts such dimensions as are no larger than will secure safety; and hence it is of the first importance to know in each particular case how high a stress may be applied without risk of rupture or of permanent

* Communicated by the Author, being the Presidential Address to the Engineering Section of the British Association for the Advancement of Science, York, 1906. 